derivado en algunos planteamientos que sostienen una posible situación de "doble poder" por períodos extensos de tiempo, distanciándose del carácter transitorio que le dio Lenin en base a la experiencia bolchevique. Para Gaudichaud, el "poder popular" chileno estuvo lejos de constituir un "doble poder", pues los comandos comunales -que fueron vistos por el MIR como posible encarnación de un poder paralelo- quedaron limitados, tanto por la débil participación de la base social a nivel territorial como por la intención de los partidos de la UP por acoplar esta fuerza activa a la transformación institucional que encabezaba Allende. En esta lógica, al menos para el caso analizado, cabría preguntarse si la categoría de poder popular constituyente es la más adecuada para distanciarse -tal como pretende Gaudichaud- de aquellos planteamientos que equiparan la autoorganización obrera con el poder estatal. Quizás sea mejor hablar de fuerza social constituyente, dado el carácter más líquido y oscilante, que se nutre de diversas experiencias fluidas, tal como remarca permanentemente el autor sobre el poder popular.

Con todo, el libro de Franck Gaudichaud es indispensable para el debate académico y político en Nuestra América, al ofrecer herramientas críticas para rescatar aquellos "tesoros" perdidos en el océano de la historia, que muchas veces las clases dominantes buscan sumergir y borrar del mapa, pero que permanecen en la memoria y pueden servir para comprender otros procesos similares, y -quizás más importantes aún-ser pistas para concretar las utopías de cambio social en el siglo XXI.

José Ponce (Universidad de Santiago de Chile)

$* * *$

\title{
Kauan Willian dos Santos y Rafael Viana da Silva (orgs.), História do anarquismo e do sindicalismo de intenção revolucionária no Brasil. Novas perspectivas, Curitiba: Prismas, 2017, 449 pp.
}

El interés historiográfico que despertó el anarquismo como tema de indagación en las últimas décadas produjo una renovada camada de estudios que permitieron poner de relieve ciertas aristas que habian quedado relegadas en investigaciones anteriores, donde el eje se centraba de forma exclusiva en la vida sindical. El libro compilado por Kauan Willian dos Santos y Rafael Viana da Silva, História do anarquismo e do sindicalismo de intenção revolucionária no Brasil, se propone contrarrestar los análisis unilaterales que se limitan sólo a la dimensión cultural de la experiencia anarquista, al considerar que derivan en un divorcio analítico entre los ideales libertarios y su dimensión de clase. En este sentido, retoman los estudios de esta corriente desde una perspectiva política y social, y ofrecen 
nuevos abordajes para pensar sus vínculos con los diferentes ámbitos de actuación, especialmente en referencia al movimiento obrero, aunque no de forma exclusiva.

La publicación es el resultado de un trabajo colectivo, compuesta por un total de quince artículos y un prefacio, a cargo de los organizadores. La mayoría de los textos son el resultado de un ajustado resumen de tesis de posgrado, por lo cual cuentan con una gran solvencia empírica y metodológica. Este conjunto de estudios se inscriben dentro de la línea de trabajo sostenida por el Instituto de Teoria e História Anarquista (ITHA), centro que reúne a investigadores de diferentes puntos de Brasil, y en menor medida de otros países, dedicados al estudio histórico del anarquismo y al análisis de la coyuntura política desde una perspectiva crítica. El libro, al igual que anteriores trabajos del mismo grupo, fue publicado dentro de la Coleção Estudos do Anarquismo de la Editorial Prismas, la cual cuenta con Felipe Correa como su director.

Los trabajos que conforman el libro abordan una amplia variedad de temáticas, en diversas áreas espaciales y temporalidades, pero ciertos planteos se dejan entrever de forma transversal a lo largo de la obra. En primer lugar, la noción de dualismo organizacional, en tanto diferenciación de los ámbitos de actuación de los militantes entre las organizaciones de masas y la agrupación específicamente anarquista, núcleo político desde el cual se delinearian las estrategias para influenciar dentro de los diversos ámbitos de actuación; planteo conceptual sostenido por la tendencia plataformista asumida por los autores.

Una segunda característica es la determinación manifestada por los anarquistas hacia la actividad sindical, como estrategia de inserción social predilecta. Los autores denominan "sindicalismo de intención revolucionaria" tanto a la corriente anarcosindicalista (y al forismo latinoamericano), como a la acción gremial de las organizaciones sindicalistas revolucionarias que no adosaron una finalidad social a sus entidades, pero que se desempeñaban de acuerdo a prácticas federalistas, asamblearias, antipoliticas y de acción directa. Por último, otro elemento que atraviesa los diferentes textos es la revisión de la conceptualización misma del anarquismo, del cual rescatan el perfil social y complejo de esta corriente de pensamiento revolucionario, con sus respectivas discusiones estratégicas y divergencias políticas en su interior. De esta forma, contraponen argumentos históricos y teóricos a la visión simplificadora y descalificativa impuesta por el grueso de la historiografia marxista y liberal.

La organización de esta obra colectiva está estructurada de forma cronológica, partiendo de mediados del siglo XIX hasta los primeros años del presente siglo. El primer trabajo, a cargo de Felipe Correa, se explaya sobre el proceso de conformación del movimiento anarquista en América latina en relación a la experiencia de la Primera Internacional. A este texto le suceden una serie de estudios que abordan el establecimiento del pensamiento libertario en las luchas sociales de diferentes estados brasileños, como 
San Pablo (Clayton Peron Franco de Godoy), Rio Grande del Sur (Anderson Romário Corrêa) y Ceará (Víctor Pereira).

Dentro del periodo de la Primera República también hay trabajos que abordan al anarquismo desde otras aristas, como la propaganda antimilitarista, la cuestión racial y su vínculo con los grupos específicos (Kauan Willian dos Santos), el activismo feminista y la cuestión de género dentro del sindicalismo libertario (Samanta Colhado Mendes), la emergencia del sindicalismo revolucionario como estrategia propia de los anarquistas, en conexión con una perspectiva global (Tiago Bernardon de Oliveira), y el análisis de imágenes anarquistas y anticlericales desde un prisma cultural (Caroline Poletto).

Trascendiendo aquella etapa histórica en la que los anarquistas lograron su mayor repercusión social, una segunda parte del libro se ocupa de las diferentes coyunturas politicas posteriores a 1930. Rodrigo Rosa da Silva se encarga de adentrarse en el período varguista, y analiza el embate represivo sufrido por los anarquistas y la cooptación ejercida hacia el sindicalismo de acción directa. Luego, Rafael Viana da Silva, además de oficiar de organizador del libro, aporta dos trabajos en los cuales aborda las prácticas sindicales y culturales de los ácratas, uno circunscripto al contexto de la República Nova, y el otro referido al período de la dictadura militar.

Enfocándose en el análisis de la prensa anarquista, João Henrique Castro de Oliveira también colabora con dos artículos, el primero de ellos centrado en la publicación O Inimigo do Rei (1977-1988), y el otro sobre Libera... (Amore Mio) en el contexto del auge neoliberal (1991-2011). Los últimos dos trabajos manifiestan una marcada intención de demostrar la pervivencia de las ideas libertarias en las luchas sociales, y vinculan estudios históricos con coyunturas presentes. Rogério Castro se vuelca al ámbito de la educación, mientras que el artículo grupal realizado por Mariana Affonso Penna, Bruno Lima Rocha y los dos organizadores, se ocupa de los grupos especifistas, e indaga en el proceso de reorganización de los anarquistas a nivel global a partir de la década de los 80 .

Las contribuciones logradas por el libro son varias: en primer lugar el abordaje temporal de largo alcance, desarrollado a partir del trabajo colectivo, permite ver a un movimiento anarquista con altas y bajas, pero vigente de forma ininterrumpida desde finales del siglo XIX. Por su parte, las indagaciones referidas a años más recientes aportan una mirada renovadora sobre los cambios y readaptaciones ejercidas por los libertarios, en conexión con el auge de nuevas demandas sociales. De esta manera, la revisión de las categorias de análisis utilizadas en los estudios sobre el anarquismo ha permitido poner en duda las interpretaciones reproducidas por la historiografia más difundida, y estimular el conocimiento de la verdadera dimensión histórica de esta corriente. El único exceso que podriamos advertir en este sentido, se ubica en el énfasis puesto en el rol desarrollado por las organizaciones especifistas, con las cuales se desdibuja su anclaje histórico.

De la gran variedad de perspectivas de análisis utilizadas, quisiéramos 
destacar la pertinencia del abordaje global, a partir del cual se pudo vincular la dinámica del movimiento anarquista de Brasil en relación con el desarrollo de sus pares a nivel internacional, que aporta elementos para considerar que las transformaciones producidas en los movimientos sociales no dependen exclusivamente de sus dinámicas endógenas. El libro cumple con creces el objetivo de difundir una esperanza de acción constructiva a partir de mostrar los avances logrados en los trabajos de investigación sobre el anarquismo en Brasil, y al enriquecer la mirada que pesa sobre esta corriente, despejar prejuicios y aportar herramientas metodológicas útiles para la comprensión de su arraigo sociohistórico.

Jacinto Cerdá (UBA - ISP “Joaquín V. González")

$$
* * *
$$

\section{Jorge Navarro López, Revolucionarios y parlamentarios. La cultura politica del Partido Obrero Socialista, 1912-1922, Santiago de Chile: LOM, 2017}

Los estudios sobre la historia de la clase trabajadora y las izquierdas atraviesan un momento de notable vitalidad en Chile, tal como lo ponen de manifiesto las actividades e inquietudes de muchos jóvenes investigadores e investigadoras. El reciente trabajo de Jorge Navarro López, producto de su tesis de maestría en la Universidad de Santiago de Chile y publicado el año pasado por LOM Ediciones, es un importante ejemplo de esta nueva generación que revela un interés por ese cruce entre la historia social y la historia politica del movimiento obrero que anima también a quienes editamos la revista Archivos y el CEHTI al otro lado de la cordillera.

La obra explora lo que el autor define como la "cultura politica" del Partido Obrero Socialista, desde su fundación en 1912 hasta su conversión en Partido Comunista de Chile, diez años más tarde. Dado que existe una importante bibliografia sobre el POS, el autor se esfuerza por explicar que la originalidad de su aporte reside sobre todo en una ampliación de la mirada en términos geográficos. Mientras que investigaciones previas, como las de Julio Pinto, Verónica Valdivia y Sergio Grez, se concentraron sobre todo en la figura de Luis Emilio Recabarren y el desarrollo del POS en el norte salitrero, Navarro López se propone incluir en el análisis el desenvolvimiento socialista en otros lugares, como Santiago, Valparaíso y Punta Arenas, con el objetivo de contribuir a una "ampliación de la historia del POS, entendiéndolo como un fenómeno que rebasó los límites del norte salitrero y, por lo tanto, que tuvo influencia en los principales centros urbanos" (p. 16).

En la introducción, el autor presenta sus objetivos generales y explica el concepto de "cultura politica", que tiene una presencia constante a través de todo el trabajo y parece revelar la preocupación del autor por mostrar que su interés por el desarrollo político del POS no implica un retorno a 